\title{
On Tender Pain
}

\section{Abstract}

Pain is ubiquitous; tender pain is special and various. This paper roams around to meet and undergo surprising variety and warmth of tender pain that accompanies tender joy.

Keywords: joy, pain, tender, kids, violence, love, presence, imagination
Volume 3 Issue 6 - 2018

\section{Kuang-ming Wu}

Professor in Philosophy emeritus, University of WisconsinOshkosh, USA

Correspondence: Kuang-ming Wu, Professor in Philosophy emeritus in Rosebush University, University of WisconsinOshkosh, USA, Email kmvvu2002@yahoo.com

Received: October 01, 2018 | Published: November 16, 2018

\section{Book review}

Human life is constantly surrounded with pain, both as justified one and as unjustified one. Unjustified pain is violent and bestial even below innocent animals, and it is caused by offending justified pain. Justified pain is tender pain in acts of love. Love means to cherish and serve heartfelt. We are human because we love, cherish, and serve three sorts of beings precious to us.

These precious beings are our parental others, our beloved posterity, and our own self. We are absolutely and unconditionally commanded by our innate being-as-human to love and serve them wholeheartedly and constantly, no ifs and no buts. Now we must lovingly consider one by one our tender pain in love of each these three beings so precious to us. One, we ought to love and serve our parental others. None of us gives birth to ourselves. We were all born by our parents, and are at present continually being born by our parental others. Our parents are at least of two sorts, culture, and nature. To begin, our very way of acting and behaving now, our habitual way of feeling and selfexpressing, and our constant mode of intending the world-they compose our being human, and they are our parental heritage in which we move, live, and have our very being. We are born cultural.

All this while, as we live our parental culture, we constantly revise it, "improve" on it, and develop it in a new direction with new quality that not even we ourselves have anticipated before. Both our dear cultural past and our spontaneous living on at present are forwardlooking, constantly on the move into creation of novel future. We inherit yesterday to live today, so as to create tomorrow totally new and fresh. This is how we spontaneously love and serve our parental others called our "culture." In addition to our cultural parents, we are constantly being given birth to by our Mother Nature. She constantly raises us and allows us to grow up into our inviolable dignity of selfintegrity. It behooves us then to love and meticulously serve our Mother Nature. Our eco-piety is our cosmic filial love that serves the preservation and promotion of our Mother Nature.

Even slightly slighting our environmental service in our filial love devastates Mother Nature, and in ecological disasters that we perpetrated, we simply perish without a whimper. Our love of Mother Nature makes us thrive. We live breath to breath with Mother Nature. Our filial eco-piety of Mother Nature feeds us and enriches our very lives. In all, our self-integrity consists in being with our parental others, our culture and our nature. Two, we ought to love and serve our beloved posterity. Our dear children are angels dropped from heaven. We have no ugly angels anywhere; all our beloved angels attract us and no one can oppose such attraction by them that they do not even contrive. And these angels of our beloved children have absolute authority over all of us. We simply must hear and obey them, to serve their daily needs. Interestingly, while we hear their needs and serve them, these angels - without even trying - spontaneously cleanse our unwanted dross, and we ourselves now turn angelic.

Of course, we used to be angels ourselves under meticulous care of our parents while we were their beloved children. Strangely enough, however, as we grow up, we grow out of being angelic into some sort of monsters, and we turn ugly and misbehaved. And then, it is time to return to our new angels with whom we are entrusted. We now ought to hear their needs and obey their need-authority to serve them, and they will spontaneously cleanse us out of our ugly monster-dross. We come to be angelic again, thanks to our obeying the absolute authority of our beloved angels and their needs entrusted to us. Their needs are ours to care for. And our caring for them cares for our homecoming to becoming angels out of heaven.

Three, we ought to love and care for our own self. In our loving and serving our culture and Mother Nature, in our loving, obeying, and serving our beloved angels, we usually spontaneously serve our own needs, by clothing us out of chill, feeding us out of hunger, sleeping us out of fatigue, and cleansing us unsoiled and unspoiled afresh. We may not realize that caring for our own self often redounds to caring for our neighbors close by us. Our self-care teaches us on our neighbor-love. We now come to "love my neighbor as myself," as if nothing is the matter. And nothing is really nothing special in all this. Mutuality is our inherent health of humanity and the converse is also valid. Compassion for others is not for others. Other-compassion naturally cares for oneself. We must learn from our self-care to care for my neighbors one by one, each in her specific ways. And we must learn from our failures in our other-care to adjust our own self-care appropriately to promote our own natural health. Again, mutuality is the essence of human health. Of course "care" means "trouble" in tender pain. Caring is tender pain to promote mutual health invigorating life. Caring in tender pain is completely justified.

Now, violating such justified tender pain described tenderly above plunges us all into violent pain of all sorts, all totally unjustified. Violation of justice turns things violent without rhyme or reason. Violation does violence. Eminent examples readily come to mind. Two of them stand out for attention. Both are so disastrous that we cannot help but notice aghast. They are the ancient Roman Empire and recent Hitler. After two centuries or so of Pax Romana, corruptions of all sorts erupted and extended all over, so much so as to invite disastrous sack of Rome by the foreign ruthless barbarians. Violence at home and abroad collapsed the great Roman Empire. By the same 
token, long ugly history in China tells us that people can be oppressed only so far, and no more, without tragic consequences.

When the brutal royalty went beyond this certain and absolute limit, people were aroused into "raising justice" in revolt, and solidwood series of royal palaces so fabulous would burn for many months. Countless eunuchs and concubines then fled, scattered, and hid away in countless places. The royal heads kept being chopped off one by one. And these royal heads would roll on the bloody ground. It is such a tragic sight to behold. We sigh. Now, here is a second tragic example. In recent years, a botched student of painting called "Adolf Hitler," with one eighth of Jewish blood in him, came to impose blame on his fellow Jews for his own failure in painting. Of course such an imposition of blame, blaming one's private failure on other fellow human beings, is insane and completely unjustified.

He insanely tried his "best" to use his enormous rhetorical talent to keep up his demagoguery. He managed to fan up his private hatred in narcissistic mass-murder throughout Germany. But his worst struggles only lasted four years, and he had to kill himself in an underground bunker. Hatred harvested only lethal hatred, all so shameful. All Germans today are too ashamed even to mention "Adolf," much less "Hitler." Again, violence ended in violence so stunning so unjustified. Such ghastly incidents of violence continued to come in ugly history only to go away, again and again. They continue flaring up as "flowers of fire" as Japan calls them, noisily cracking up the dark sky as firecrackers, impressively displaying insidious spectacles and then vanish away somewhere unknown. Incidents of violence unjustified are only noisy firecrackers so empty and so sadly tragic, for no reason whatever. Just ask Hitler why he hates his fellow human Jews, and he would never be able to answer.

And so, this ubiquitous fact cannot be repeated too often. Sex is joy because sex shares its pleasures. In contrast, Hitler's mass-murder hatred is his sadistic pleasure staying one-sidedly with him alone, without sharing it with his massive victims. Of course, it took Hitler's enormous talent of demagoguery to keep up such sadistic satisfaction, but still it actually collapsed in just four years. Brutal dynasties in China's ugly history and elsewhere did last a few centuries, but they all ended in disastrous revolutions, all so bloody. Violence on the others has never lasted for ever. World history testifies to this solid fact worldwide, that no violence is everlasting.

In contrast, sharing pain not only eases pain into tender pain. Sharing pain turns tender pain for a good reason. Sharing has a definite potential to potently last long and long incorruptible. Sharing pain needs struggling virtue to achieve itself by expressing itself, to stand itself incorruptible. Pain sustained is shared mutual, and sadomasochistic. Pain is sustained into tender pain mutual, in mutual caring pain. Here to suffer pain is to co-suffer in co-pathos, in compassion. Mutuality is the essence of tender pain shared in mutual sensitive care. Tender pain is shared and served. There is no blinking about this solid fact of mutuality, ever. "But how should tender pain shared deal with violent pain hoarded?" Violent pain so unjustified can be countered and calmed down by tender pain in gentle persistence of "an extra mile," which can be counter-violent but in specific ways of tender pain of care. We can easily imagine a possible scenario such as this. We can use the same insidious tactic used by Hitler to insidiously kidnap Hitler, and hide him in a special secret chamber under strict surveillance and then we can threaten him with death unless he sits and listens repeatedly to the impressive stories of his own brave fellow Germans (such as Paul Tillich), risking life to save fellow human Jews, out of brutal Nazi officers. Being also innately human,
Hitler would eventually — and hopefully sooner than later - moved to human fellow-compassion for his fellow human Jewish people.

It is thus that Hitler's eruptive violence is tamed by tender pain of persistent caring. After all, violence by definition violently intrudes to violate - to destroy. We have no "everlasting violence." In contrast, tender pain of gentle care patiently persists to tend life and promote life. Tender pain would never quit until life stands invigorated and incorruptible. Tender pain in gentle care persists. Such patient pain is everlasting over sudden jerks of jackrabbit violence. Tender pain embraces violence of any sort.

Now, we have another sort of tender pain, never to be neglected though seemingly so casual. It is missing someone cared for. "Caring for" here may not always be being loved, for I used to miss Nixon when he finally resigned, because I then had no one to kick around with any more, but of course I did not love him. Still, his case is special because I doubt if I would miss Trump when he is gone. But Nixon is an unusual case for me.

Usually I would miss someone beloved. In missing her, I am starkly confronted with my craved-after presence that is nowhere here now. Such presence of absence composes my missing someone I love. You can understand missing someone beloved is as painful as helplessly in love with someone. The tender pain of loving someone so unbearable is equivalent to its negative mode, missing someone beloved so helplessly.

As of now, I do not know what it means, what use I can make of it, if any, and how beneficial or harmful it can be. I just notice that missing someone beloved is pain unbearable often, though tenderly sinking me down often. The parents, say, are simply overwhelmed with joy to welcome their child to come back home for vacation from schooling, and just miss him unbearably when he has to return away to school as fully expected by all parties concerned.

Now, again, don't ask me why or how such pain and such joy happen, even while they are fully expected. The parents are always like that. That is how silly the parents are. Still, such pain of missing someone beloved is tender and much substantial, I can assure you. Loving someone and missing the beloved are perpetrated by the same power of tender pain that numbs us helplessly. Such is the phenomenology of love, the existential logic of the appearance of love.

Missing someone beloved is never to be taken for granted, much less to be brushed aside as unimportant, for such pain is quite substantial, even enormously unbearable at times. But still, we have not heard of anyone dying of missing someone, however unbearable such pain may come to be sometimes. In missing someone beloved, we are simply and totally helpless. No friend or relative can help us, though they can silently be with us sharing meals so lonesome so unbearable. Again, do not ask me why or how no one has died of missing someone. Missing someone simply happens often, out of the blue or perfectly expected. And I do not know what to do with missing someone, either. I am simply engulfed in missing someone, all so helplessly.

And so, cherishing someone and missing the beloved demonstrate and typify the strange power that benumbs us into tender pain all helpless. This power is love that does not conquer as any traditional hero does. This power of love simply collapses anyone who is afflicted with such an impossible disease called love. Love melts away all persons with sense into the pit of helplessness so benumbing. 
No big Goliath or small David, both so powerful in their own ways, can face up to this power of love. Love is more deadly than death and more benumbing than hell. We simply collapse into love by the sheer power of love. Remember the almighty King David was totally conquered by a nameless, powerless, and completely obscure lady simply taking her daily casual bath. In love, she turned out to be the mother of no less than the almighty King Solomon! Love gives birth to all kings almighty, by benumbing all kings almighty.

Tender tiny pain of love has an amazing power that draws us and benumbs us. Such power is never masculine and overcoming what opposes. On the contrary, such power yields to yield tender pain, benumbing to feed, giving us home to rest, and rendering us helpless as it supplies us with power that begins to yet to begin. Tender pain is the growing pain that begins and grows us into our true self. Such benumbing power in tender pain does not conquer but draws and enables, as it supports us from underneath us. Tender pain here is our growing pain. Tender pain does not cut into us, but it still bothers us somehow. The pain here is tender. All tender pain can turn into growing pain.

And then I suddenly realize. I notice that almighty, benumbing, and growth are suddenly mentioned together and thrown together into a comprehensive pot of some sort. The power that does all such, I simply cannot find. "What does all these acts" must then not be an objective power. It must be that "in which" thing move, live, and have their being. This "in" must be what is responsible for things growing up into themselves. This "in" must be the "environment,"

An environment environs, surrounds, and enfolds. An environment is not an object but a strange entity that embraces and enables inside things but not things themselves. "Environment" is then a sort of enabling power that is no power but what enables power to be power, a sort of power to let things grow. But let-power is no power. Such power does nothing but lets things do as they do themselves freely. The power that lets do freely is not power that itself does. Such nopower power is the environment, pure and simple Environment is then not any object or objective power, but that in which things grow. But environment itself cannot be objectively looked at, and so when we look at the environment invisible, we turn numb. We have no word to express such benumbing effect, so we call it "tender pain" that is really not pain but tenderness inexpressible. Inexpressible tenderness is by-named "tender pain." Thus it is that our tender pain strangely benumbing is actually our environment all indispensable to our very existence. Environment surrounds us. Environment is that in which we move, live, and have our being, to grow into our own self. Environment is our self enabled.

Thus it is that we have finally captured what can never be captured as an object or objective power. It is a strange womb called our "environment" that environs us as a greenhouse within which we are constantly given birth to, raised up, and let grow into our true identity. We feel numb as we go through our own process of growing. Our feeling dizzy is healthy tender pain of growing, as if the pain of cutting our teeth that we cannot help but feel is nothing extraordinary.

What can be felt here can only be felt as "tender pain" that is actually our healthy growing pain of a sort. If there is no such "tender pain" of such sort inexpressible, then there would be no growth, of which we are never aware. Now we know that "tender pain" is a misnomer, but we let it stand as we use it, as we can find no other suitable name. And so, we continue saying that tender pain is our growing pain, fully knowing that growth is actually no pain but a benumbing discomfort within an environment that we can never objectively realize. St. Paul also struggled and groped around with the ancient Greeks so wise, and he finally even had to call such environment our "God," reported Acts 17. Our God is that Great Environment in which we are born, unawares and benumbed, as we continue to move and have our being in it. Something like this is also faintly hinted at in Genesis One and Genesis Two, and brought forth as an environment by Paul in Acts 17.

We can thus see how the human Bible itself struggles with us to express such primordial Origin of things, as our "environment" that environs us to womb us forth. The process of womb-ing forth and the womb itself are characterized as "God," what is really our primal environment of which we are unaware, and out of which we are constantly born to move and have our being.

In the meantime, we would now innocently talk about benumbing "tender pain" that is our birth pangs to begin our day, ever yet to begin our day at dawn so shy and dark, when the sun just peek out quite baby-shy. Our tender pain is our birth pain cutting our tender teeth, for the first time in life so benumbing in tender pain. Such is what always happens at every dawn when we arise out of our warm bed to begin our day chilly afresh, unaware of our environment that enables all this beginning of our day to take place, first time ever since the creation of the world.

Of course all above description is concocted by our imagination. Imagination feels, and feeling is tender pain. "Tender" is fun among kids who imagine and romp around all their days so enthralling. That is why they are so happy here now at present, all the time. Kid's imagination makes starkly present all monsters whom they never know on what they are, and who they love to fight because these kids are ignorant of what such monsters are,

We care for their daily needs and watch them and smile, as if we know better, without knowing that we imagine ourselves into surrounding ourselves with monsters we never know either, and fight and try to tame them for reason we never know, either. You ask those adults what their "serious businesses" are, and why they engage them. These adults would say they must engage to make money to live on. We ask them why they must engage monster-businesses to live on. And they simply stare at us, as if we are insane. Their silent stare tells of their abysmal ignorance about themselves and about all such monster-creations and monster-fights all day long.

Still, it is an indisputable fact that all of us kids of all ages always imagine. That is why we can never answer why we create monsterbusinesses to fight to manage them, for no imagination has any why or how it is as it is, starkly present as it is. And we are thereby always confronted with stark presence of the present, night in and day out. We live by engaging imagination to create environment, worlds, presence, and even monsters, without ceasing. We concoct presence so compelling to overwhelm our living days, without ceasing. That is how we come to have tender pain.

Animals on their part seem never to imagine presence. They just innocently live presence at present. Dementia also renders us living in the present without knowing it. Usually we without dementia are aware that presence pervades in our past, in our here now, and in our future, as we live through yesterday, today, and tomorrow. We cannot live without such imagined presence starkly ubiquitous and compelling.

Imagination spells joy. Kids always live their concocted imagination, and so they are always happy. Even their wailing pain chants their fun living, living their imagination so happy. That is why all of us, including their Mom, keep hugging them wailing in pain. 
Our adult imagination also cranks out joys and sorrows. Our life-task lies in steering our imagination away from sorrows toward cranking out joys of Alice in her Wonderland, and both Alice and Wonderland are joys of imagination we engage, as they were cranked out by the playful mathematics of Professor Dodgson at Oxford.

Spooky mathematics or not, we have been toying with environment, worlds, benumbing power of tender pain, and the like, and our toying is our engagement of imagination, which continues cranking out stark presence so compelling at present, ever. We simply let it go! We cannot help it, as we cannot help living on and on, and on in our voluptuous imagination into sheer stark presence so compelling, and so overwhelming into tender pain, no ifs and no buts at all.

Anyone who dares to object to such imagination would of course be immediately engulfed in imagination cranking out his own objection in his own stark presence that confronts him willy-nilly, quite helplessly. Even doubting all this is itself an engagement in imagination in sheer presence. Cynicism and narcissism are all part of stark imagined presence. Try opposing imagined presence, and you would inevitably be engulfed in stark presence cranked out by imagination.

All this is simply because all of us are alive, and being alive is being starkly present as imagined, all the time. No presence, no life, ever. Dead people alone have no presence, for even animals live immediate presence, though seemingly without imagination as we human beings have, to crank out human presence raw and stark.

The world-renowned novelist C. S. Lewis said that in his imagined world, all characters, human and non-human alike, are alive and simply doing their own things, and he just observe and describe them. Such is how his engrossing literature arrives. Hearing his confession, we are so impressed with Lewis, not realizing that we ourselves are such novelists day in and day out, cranking out in our imagination all such crazy romps and kinks without rhyme or reason.

We observe and describe such romping engagements while we ourselves romp and crank out all such insane activities ad infinitum, all thanks to our imagination. We are in this way much more than C. S. Lewis, while we are not of the caliber of Lewis at all. We the common ordinary people are absolutely extraordinary, thanks to our crazy imagination of the caliber of Alice in her Wonderland.

And, incredibly, as we create Alice and her Wonderland, we ourselves become she and her Never Land, all thanks to our voluptuous imagination. We live imagination in stark presence. We are alive and present at every moment, and such "every moment" begins to yet to begin fascinating world of Alice in her Wonderland that is all ours, and no one else's.

All the unimaginable worlds all imagined are the essence of all our days of life. Our life so reasonable is our life so unreasonable and so beyond sense and sensibility. To realize such stark presence all imagined is to live it up, full and exciting as all kids are so fascinating in all their fabulous imaginations, world without end, to create with imagination all those fantastic worlds unimaginable.

Such unlimited imagination is ground to a halt only by droning trivial grind of daily chores such as deleting junk emails, but not eating daily meals with gusto, however many times we repeat enjoying them. Repetition can become fascinating rhythm of living. We live taking deep breaths at the breathless scenery. Breathless scenes can repeat the rhythm of wondrous sighs, repeating without ceasing. Now our lifeworld is fascinations continually repeated, and no single one in the world would even think of objecting to such repeated fascination. Fascination is more fascinating as it is repeated all the more.

No wonder the kids always insist, "Do it again!" Happy kids want repetition of happy fascinations, world without end. Endless repetitions of endless fascinations compose endless joys of happy life of those kids of all ages, the end. And the kids say, "Do it again!" O boy! All C. S. Lewis and all Dodgson and even all Einstein are here smiling. All of us are all kids of all ages, all in fun imagining, world without end. "Do it again!" O boy! We cannot win! All this victory is won by invincible imagination that cranks out all our lifeworlds, all environments, all presences, and even all tender pain, all so compelling at stark present.

Merely to be alive as human is to be helplessly engulfed this way in voluptuous imagination of Alice and her Wonderland, in which we all live as our incorruptible environment. No such all-embracing environment would stop all such fascination of being alive as human. In the beginning is imagination, irresistibly creating all unimaginable worlds of this world beyond this world. To oppose all this imagination takes imagination to do. There is absolutely no escape from this allinclusive imagination, world without end.

Presence presents here now to confront us face to face, and we have nowhere to hide. Kids simply confront stark presence point blank, and play with their here and their now. These present moments come, only to come again, to bring song birds here and there to chant the accolades of sheer presence totally fresh and jumping alive. Those kid-presences romping around are filled with songs so silly and so enthralling.

The presence fills the self to overflowing in joys of life, all brimming with the innocent dawn still shy and dark, fragile with cooing dove and chirping birds. No one can defeat such kid-presence so beautiful and so dawn-enticing; all of us are all won over, all drunk with hilarity of tender pain in growing kid-pain. Kids continue to grow in their tender growing pain. "Do they mind it?" Well, they just enjoy every minute of fun living, so much so that they do not even what is "fun," "living," or "day."

Presence is chock-full of such hilarious silly kid-songs alive booming and spreading, on and on without a single opposition. Presence is the kid who compels raw and inescapable. Presence overwhelms here now with inexpressible kid-vitality with no sense or rationale whatever. In fact, presence is sheer presence completely without raison d'être of whatever sort. On the contrary, it is raw presence that gives rise to whatever excuse to whatever existence there is that exists.

Everything must seek its excuse of being here now in this stark presence. It is presence that compels things to come up with their excuse of being here now in the first place. If you say you don't know what I have been talking about, you must go be embraced in babypresence in silence. You would then understand without any rationale of whatever sort. I on my part am all too busy being enwrapped in raw presence to even care to bother noticing you scratching your head.

Reasonable or without reason, excusable or inexcusable, sheer kid-presence simply comes and comes again, to fill up whatever there is as present alive and skipping all over. Presence simply overwhelms to compel things and challenge things to make sense of them as they. This is the primordial categorical imperative of mere existence. Anything that exists must fulfill this obligation.

Kid-imagination so primordial is responsible for such existential 
imperative absolutely categorical. This basic imperative is adequately responded to and fulfilled completely, only by sheer power of raw presence cranked out by our innate kid-imagination. Our powerful imagination is all so kid-benumbing in tender pain, all kid-tender in kid's growing pain.

It is thus that, in such a way as this, stark presence solidly anchors here now my self-integrity, while at the same time my voluptuous imagination soars me far and away into the vast horizon unimaginable. Such growth is attended with my tender pain that attends cutting my baby-teeth. Tender pain is the joyous pain of growth that defies all pain on all occasions, for nothing can conquer growth. This is because we are all won over by the baby, as nobody can object to the beginning of life. Stark presence in imagination starts the rest of life.

Being humanly executed, all rational arguments should be "infected" with feeling. The greatest of feelings is joy. This must be one of the connotations, among so many, of St. Anselm's ontological argument for the existence of God. The entity than which nothing is greater must exist, because such an entity "in mind and in actuality" is greater than this entity "in mind" alone. This ontological argument is a joyous stroke of genius. Kant's objection that attribute is not existence is a quibble. $\$ 100$-in-pocket is greater than $\$ 100$-in-mind because the former buys, not the latter. So, the greatest must actually exist beyond being thought about. This greatest of being that exists is called "God."

In addition, this greatest of all existents must be joy. Joy is the greatest. Joy is God. One demonstration of joy as the greatest is that joy is toughened precisely by its enemy, disastrous sorrow. Joy does not just defeat sorrow. Joy is strengthened by sorrow. No power is greater than the one that is toughened precisely by its enemy meant to destroy it. An explanation of how this is so is in order here.

The hollow in the bamboo serves to strengthen the bamboo. A broken bone healed is stronger than the one not-broken before. Crisis can double life and doubly enhances one's life-career. Job and Jeremiah who cursed their births under disasters were awarded with joys later, through neither may aware that their sorrow may have produced their joys.

Thus it is that human extremity is divine opportunity toward joy. When these things raise their ugly head of threat of destruction, it is the occasion when we must raise high our proud heads of joy, for our joy will be toughened precisely by those sorrows that are meant to destroy joy. Joy is greatest through its enemy that toughens joy. Therefore joy is actual and not hollow speculative. And joy amply deserves to be actualized. The argument for God is the argument for joy. This argument argues for our existential imperative to actualize joy almighty and divine, as such joy on its part supports us through our darkest hours to toughen joy through its enemy of disastrous sorrows.

Joy is absolutely fabulous when wrested from its enemy that is taken advantage of to serve as foil to toughen joy. Thus joy is so great that we can forget our self in it, in contrast to sorrow that sticks us to us, as Job and Jeremiah were stuck in their selves so much as to curse their own births, and their painful sorrows rewarded them with exciting joys that doubled the amount of their previous sorrows. Austerity of sorrow feeds hilarity of joy. This amazing fact impressively demonstrates how divinely omnipotent joy is.

Joy, joy, and more joy should be our task of life, the purpose of our being alive at all. There is no life when there is no joy. The graveyard so quiet has no joy. Dead people do not strive after joy. Joy is the sign of vitality. Where there is joy, there is life, and when life is active vigorously, joy is being created and promoted quite actively.
And joy is actively seen precisely in disasters that are being used to produce joy and promote joy. Joy driving sorrow to increase joy is thus incorruptible, ever, precisely through sorrowful destruction.

Opposing destruction begins construction. Where there is destruction, there lurks the beginning of construction. And construction is joy that begins. Thus it is that joy invincibly begins to yet to begin all things. The beginning is all-powerful exactly as joy is all-invincible. This is because, among others, the beginning is what is universally desired by all beings. Things continue to blossom due to Mother Nature beginning at every single moment. Not a single person in world history would even think of opposing such delightful beginning of things.

Joy that begins from scratch, even out of disastrous sorrow, is God who creates out of whirling wind of chaos of "nothing" in particular. Divine whirlwinds continue to blow against arbitrary chaos. It is such random chaos that provokes divine creation. It is disastrous sorrow, soon to be over, that feeds invincible joy to blossom joy all over all the time. No temporary chaotic sorrow, no incorruptible joy divine and eternal. Death is never eternal in the face of such stubborn joy of constant creation.

Contrary to our abject assumption that "nothing" lasts, "nothing" never lasts for ever, but ever conquered by persistent joy of divine wind ever doggedly blowing over disastrous-nothing. If joy thrives precisely over its destructive sorrow, joy is all-powerful thanks to its destructive enemy of sorrow. Sorrow is only temporary, and we must be convinced of this incredible actuality. Sorrow is a farcical tool used by dogged joy to strengthen joy; we must repeat to our soul this incredible fact.

Again, we must remind ourselves. All rational arguments are infused with passions, and all passionate arguments argue for persistent joy invincible, ever. If it sounds like an impossible Pollyanna, joy taking advantage precisely of its enemy the disastrous sorrow should convince us that this Pollyanna-joy is real and integral, waiting to be lived with gusto, precisely during the darkest hours of sorrows. Joy displayed by sorrow is our solid incorruptible fortress of life that our life ought to do its best to prop up and prosper to its bitterest end through darkest sorrows.

Joy displayed by its enemy sorrow is incorruptible, and we must doggedly display such incredible joy through thick and thin, for better and for worse. This is our unconditional command imposed on our living days, no matter what, come what may. And such performance of joy during sorrow is itself joy that defeats sorrow. We simply must grit our teeth and try joy, and joy will cut our baby-teeth to begin things to yet to begin life of all things.

Joy simply begins things against all things, no question is asked, and here nothing can be asked. Only the command of joy remains, all so delightful, as the command to joy is itself joy invincible, to include and take advantage of even its enemies of sorrows and disasters. All this sounds hollow and as incredible as Pollyanna, until we actually try joy, even gritting our teeth against sorrows, and our teeth will taste surprised joy of obtaining joy through all our sorrows and disasters.

We must always remind ourselves of this fact that sounds so incredible. Joy always begins against all odds. Joy is much tougher than we expect. And so joy always surprises us, who are usually abject and timidly daunted. Our cure-all of such abject timid "realism" is joy, simple and straight, tough despite all. Tough "despite" always accompanies joy to conquer all things, to embrace us bravely during the darkest hours. 
Again, if you are not convinced - and it is hard to be convinced, isn't it?-you simply must try joy. The proof of a pie lies in tasting it. The proof of joy as tough and invincible remains in trying it, convinced or otherwise. Just try joy, and you will for sure like joy, as absolutely no single person in the entire world resents joy at all. Tears of sorrow will soon turn into tears of joy, as all persons are defeated with joy by joy, always.

Such indisputable fact of joy implicates an inevitable imperative to assiduously promote joy, precisely during the darkest hours of sorrow inconsolable. Joy is priceless and irreplaceable by anything else less than joy, as joy is the sole and highest desideratum there is in our life that is often a vale of tears of sorrow. Indisputable fact of joy implicates inevitable imperative of joy. No objection can be expected at all. Pollyanna optimism is sure to stay as solid actuality, to be actualized at all times, unconditionally.

Absolutely no argument can be advanced against such Pollyanna joy, all so invincible. If argument does not convince our feeling, actual performance however we feel will perforce actualize joy despite all our hesitations that seem irrational. Actualization of joy defeats hesitation on joy though desired actually. Actualization of joy to fulfill the unconditional imperative of joy is our salvation out of hesitations in cynical "realism." We would now be convinced that Pollyanna-joy is more realistic than cynical "realism" so called. Pollyanna is realism in joy; all this is so surprising.

Being pervasively desire by all of us, and all-inclusive of even its enemy as its tool, joy is simply invincible and inevitable throughout the world. And joy cures us of all evils, such as doubt, cynicism, "realism," daunted hesitation, and all such seemingly reasonable oppositions to joy that is daring and all-defeating. Thus it is that joy absolutely demands us to implement at all times, even while we are drenched in tears of sorrows in disasters.

We simply must grit our teeth and struggle for joy, all so breathless and daring. Such unconditional demand of joy sounds unreasonable and atrocious until we try it, and then we find that it is we ourselves who are fabulously benefited by joy that makes us rejoice beyond our wits, all heartfelt. We can never deny such "atrocious" joy! We can never refuse to obey such unconditional demand of joy that is our unconditional happiness, after which all our life days strive.

The imperative of joy telling us to implement it for better and for worse is categorically unconditional, simply because such joy is categorically unconditional. Our struggles incur tender pain, to be sure, but such pain is tender and all justified. If life is an ocean of pain, tender pain striving for joy is pain that lifts us out of pain while remaining inside pain.

Joy is pain out of pain, all so justifiably fabulous. Tender pain of this sort is justifiably enjoined us. We can afford to repeat such tender pain for joy in love, a thousand and one times, and more. We are in tears of pain in joy as we struggle for joy in such tender pain. We call such pain the tender pain in love of life for better and for worse, unconditionally, come what may.

When Menuhin's violin sings silence so intoxicating, I swing in it, forgetting me in it. It is a new world alive afresh, compelling in silence so loud. Tender pain seeps in unawares. The world is totally eternal, all endless and indwelling. I am drunk delirious, and dizzy. All this while, I continue to sway my self, swinging my head and my heart without ceasing, world without end.

Am I sick? I must be sick with sonic beauty, of the magic violin of Menuhin. Fast or slow, slow and fast, I just got carried away far, somewhere unknown, and I do not care, for I do not how to care inside this delirious sonic horizon. When it finally ends, all of a sudden, I wake up, looking around, out of some sort of spell so magical. Have I been swindled, switched with another person, and bewitched away out of myself?

Surely I was far away from my self, which is yet embraced and swung all over eternally - here now. I look around, and Menuhin's violin is found still here now, booming in silence so enticing. Now I feel tender pain in the neck, in my stomach, and all over around me inside me. I must have caught a sort of cold called "Menuhin disease," a dis-ease that is still brewing tender pain all over inside me.

I have to get up and walk around for fresh air, which is another silent music of a sort. And then I would perhaps sit down again for another sort of music, a quintet of Bruckner, perhaps. "Perhaps" is repeated because I am not sure. Music makes me not-sure of anything. I am a zombie whose soul is tricked away by music out of me. Music makes me into a zombie.

And then, when that strange Bruckner-beauty sounds again, I am in delirium again in a strange way. Bruckner is a strangely different wine from Menuhin's intoxication. I sway in Bruckner in different way again, not knowing where I am going. I am only being sure of going somewhere. I am "being" sure because I am being in that situation, moved into that "being" by music. Music moves me without moving me, as you know.

Bruckner is another sort of sonic wine filled with another sort of tender pain delirious. I continue to be drunk this way until I get too tired to continue this way, but "what this way is" is eternally unknown, and I could not care less about my ignorance, either. My ignorance is contained in me all embedded drunk in musical wine, and I am now so drunk and so dizzy that I wobble into sitting down. Music is such a magic of tender wine in tender pain continuous.

The magic of music is quite amazing due to its extremely peculiar structure. Music is a peculiar environment. Usually, an environment is a stable context hid implicitly behind explicit activities to support the agent of these activities. Music-as-environment in sharp contrast is quite apparent never hidden, totally explicit never implicit, and dynamic throbbing in rhythm, ever moving to actively move us the agents.

In this special environment of music, we the agents are shaken and moved ourselves, far much less than being tacitly supported from behind as usual environment does. As a result, we the agents are embraced and drunk delirious, and dizzied in tender pain, being sick at the stomach. We are rendered soul-sick in music. Music sickens us to the core, even sickens us to near-death but without ever actually dying at all. Music is the sickness unto death that never dies.

Such is the intoxicating power of music all invisible and yet absolutely tangible, moving the mountain of the agents. The agents change the objects outside them, without ever changing themselves. Music supports such active agents far much less than positively and actively changing the agents, to wit, moves and transforms the agents themselves who are our total selves. Being moved by the environment called "music," our tacit background now turns into explicit worlddevastation in world-transformation that shakes us the agents to the core.

The agents are active intruders into the world. Music intrudes into these intruders to shake them upside down. Music is the soulrevolution. Music is the soul-shaking transformation of our total self that is by nature the transformers. Music transforms these very 
transformers. No wonder, we the transforming agents feel sick at the stomach, with tender pain all over and inside out. We so active are now rendered all-helpless inside the music that shakes us heartfelt and soul-total. We are mortally drunk sick, with the sickness unto death that never dies, called "music."

Being musical is to throb in coherent rhythm. Being musical this way, seemingly spooky, is actually surprisingly ubiquitous throughout the entire universe among all living things. At least two incidents readily come to mind, to show this musical fact so amazing and yet so ordinary. They are our common blood throbbing through our body, and our constant breathing with the trees surrounding us. We now consider them one by one, first our blood, then our breathing.

To begin, even our blood so ordinary that we take for granted constantly throbs through our whole body in rhythmic regularity, to moisten our body, to feeds our self, and thereby to invigorate our days anew afresh at each moment, always in coherent rhythm so musical. We can see how important this musical fact of blood circulation is. Strangely, however, we are usually totally unaware of this musical rhythm of blood that is our very being alive. Perhaps our being unaware of blood tells of blood being so common that my friend wonders why I have to mention "blood" at all.

Still, however, our common blood on the musically rhythmic move is so momentous and ubiquitous as to make us alive in the first place. This is why we would instantly bleed whenever we are cut or injured, no matter how slightly. Our bleeding anywhere in the body shows how our blood is throbbing musically all over all the time, awake or asleep. day and night. Being alive is being musical. Our common blood throbbing shows us so.

In addition, even our breathing so automatic (to us) is to be actualized by breathing with the common trees around us so casually. What the trees exhale as their waste, oxygen, is the fresh air that indispensably sustains human breathing, to keep human persons alive. What human beings exhale in turn as their waste, carbon dioxide, is an essential nutrient that keeps these trees alive vibrantly. Such is quite an impressive mutuality of inter-species symbiosis, indeed. And this symbiosis is, mind you, regular, constant, throbbing, and coherently rhythmic. Symbiosis is musical. Inter-species mutuality is musical.
Now, mind you once more. Being musical of the above sortsin blood and in mutuality - is essential and indispensable. Being musical is being alive itself. No music, no living existence. Our blood throbbing musical, our breathing rhythmic musical—both are musical as living itself. We cannot casually put being musical aside as if it were our dispensable luxury, to pick it up only when we take our fancy in it. No, not at all can such being musical be.

At precisely the moment when we cease to be musical, at that moment we cease to exist and turn dead. We are so constantly alive that we take being alive for granted, unaware that when we stop being alive, we stop our life. We are so constantly being musical that we take living in music for granted, unaware that when we stop being musical, we stop being alive. Being musical is being alive. This fact can never be mocked without inviting instant perdition.

Finally, we must take note of this fact so common but often not noticed. And this fact is not unimportant. It is that any amount of energy expenditure always involves some "tender pain," slight or not, unaware or not. As our blood throbs, and as our breathing happens, tender pain is there in blood and in breathing, however slightly, however tacitly. We even notice such tender pain sometimes, though we often neglect it in our daily engagement.

Such tender pain is our growing pain happily accompanying our being musical, and being musical is being in joy ubiquitous and invincible. Tender pain is happy pain. Even the glorious red leaves of the maple trees tell of the trees burning tenderly in the crisp autumn. And "burning" here indicates some sort of tender pain. So, these aspects of being musical involve "tender pain" to keep beings alive for better and for worse. Being alive in being musical involves being engulfed in tender pain, happily as can be. Strangely as it may seem, pain so tender here can be invincibly happy. Happy unconditionally forever is tender pain.

\section{Acknowledgements}

None.

\section{Conflict of interest}

Author declares that there is no conflicts of interest. 